\title{
Substrate Availability of Mutant SPT Alters Neuronal Branching and Growth Cone Dynamics in Dorsal Root Ganglia
}

\author{
Byung Kyu Jun, @Ankush Chandra, Dika Kuljis, @Brian P. Schmidt, and Florian S. Eichler \\ Neuroscience Center, Massachusetts General Hospital, Boston, Massachusetts 02114; and Department of Neurology, Harvard Medical School, Boston, \\ Massachusetts 02114
}

Serine palmitoyltransferase (SPT) is a key enzyme in the first step of sphingolipid biosynthesis. Mutations in the SPTLC1 gene that encodes for SPT subunits cause hereditary sensory neuropathy type 1. However, little is understood about how mutant SPT regulates mechanisms of sensory neuron and axonal growth. Using transgenic mice overexpressing the C133W SPT mutant, we found that mutant dorsal root ganglia (DRG) during growth in vitro exhibit increased neurite length and branching, coinciding with elevated expression of actin-cross-linking proteins at the neuronal growth cone, namely phosphorylated Ezrin/Radixin/Moesin. In addition, inhibition of SPT was able to reverse the mutant phenotype. Because mutant SPT preferentially uses L-alanine over its canonical substrate L-serine, we also investigated the effects of substrate availability on DRG neurons. Supplementation with L-serine or removal of L-alanine independently restored normal growth patterns in mutant SPTLC1 ${ }^{\mathrm{Cl} 33 \mathrm{~W}}$ DRG. Therefore, we report that substrate availability and selectivity of SPT influence the regulation of neurite growth in DRG neurons.

Key words: dorsal root ganglia; Ezrin/Radixin/Moesin; L-alanine; L-serine; neurite development; sensory neuropathy

Significance Statement

Hereditary sensory neuropathy type 1 is an autosomal-dominant disorder that leads to a sensory neuropathy due to mutations in the serine palmitoyltransferase (SPT) enzyme. We investigated how mutant SPT and substrate levels regulate neurite growth. Because SPT is an important enzyme in the synthesis of sphingolipids, our data are of broader significance to other peripheral and metabolic disorders.

\section{Introduction}

Hereditary sensory neuropathy type $1(\mathrm{HSN}-1)$ is a disorder of the peripheral nervous system (PNS), leading to progressive axonal degeneration and sensory loss accompanied by symptoms of lancinating/shooting pain. The SPTLC1 gene, which encodes for subunits of the enzyme serine palmitoyltransferase (SPT), is mutated in HSN-1 (Bejaoui et al., 2001).

Normally, SPT initiates the de novo synthesis of sphingolipids, specifically the condensation of palmitoyl-CoA with L-serine. In HSN-1, however, mutant SPT loses enzymatic selectivity and in-

\footnotetext{
Received April 6, 2015; revised Sept. 2, 2015; accepted Sept. 2, 2015.

Author contributions: B.K.J., A.C., D.K., B.P.S., and F.S.E. designed research; B.K.J., A.C., D.K., and B.P.S. performed research; B.K.J., A.C., D.K., and B.P.S. analyzed data; B.K.J. and F.S.E. wrote the paper.

This work was supported by the National Institutes of Health (Grant R01 NS072446) and the Deater Foundation (F.S.E.).

The authors declare no competing financial interests.

Correspondence should be addressed to Dr. Florian S. Eichler. Department of Neurology, Massachusetts General Hospital, Harvard Medical School, 55 Fruit Street, ACC 708, Boston, MA 02114. E-mail: feichler@partners.org. DOI:10.1523/JNEUROSCI.1403-15.2015

Copyright $\odot 2015$ the authors $\quad 0270-6474 / 15 / 3513713-07 \$ 15.00 / 0$
}

corporates L-alanine as an alternative substrate (Gable et al., 2010). The enzymatic promiscuity of mutant SPT is suggested to be the cause of pathology (Eichler et al., 2009; Penno et al., 2010). Despite the known deleterious impact of mutant SPT in HSN-1, how it regulates the mechanisms of axonal growth in sensory neurons remains poorly understood.

Here, we isolated dorsal root ganglia (DRG) neurons of transgenic SPTLC1 ${ }^{\mathrm{C} 133 \mathrm{~W}}$ mice, which overexpress the C133W SPT mutant (McCampbell et al., 2005). Neurite growth in vitro was assessed by analyzing length, branching, and the expression of p-ERM actin cross-linking proteins at the neuronal growth cone. In neurons, p-ERM is localized at neurites and growth cones, links the cytoskeleton to plasma membrane proteins, and is important for growth and axon guidance via modulation of the actin cytoskeleton during normal and regenerative growth (Gonzalez-Agosti and Solomon, 1996; Haas et al., 2004; Khan et al., 2013). We confirmed the effects of mutant SPT using myriocin, a potent SPT inhibitor (Wadsworth et al., 2013). Further, we manipulated the availability of SPT substrates to determine how they influence SPTLC1 ${ }^{\mathrm{C} 133 \mathrm{~W}}$ DRG growth. Because previ- 
A
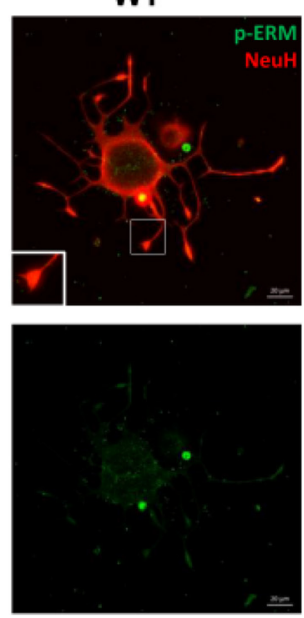

C

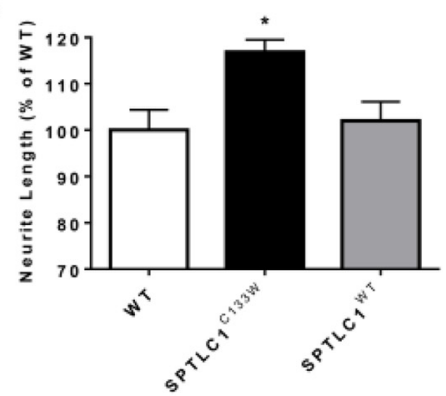

E

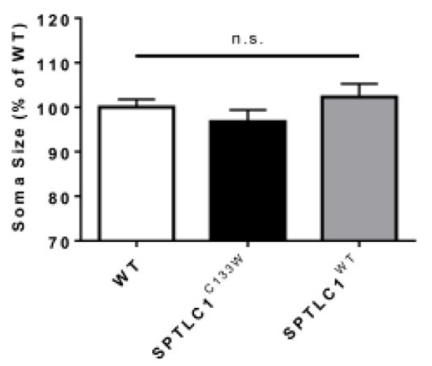

SPTLC1 ${ }^{\text {C133W }}$
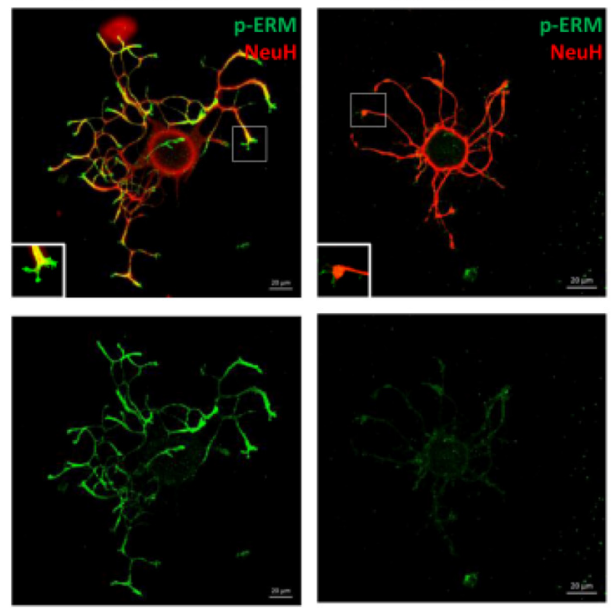

SPTLC1 ${ }^{\mathrm{WT}}$

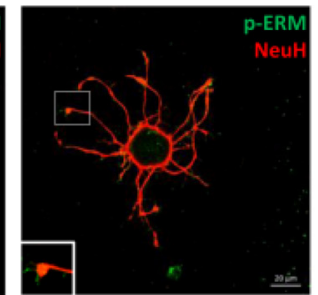

D
B
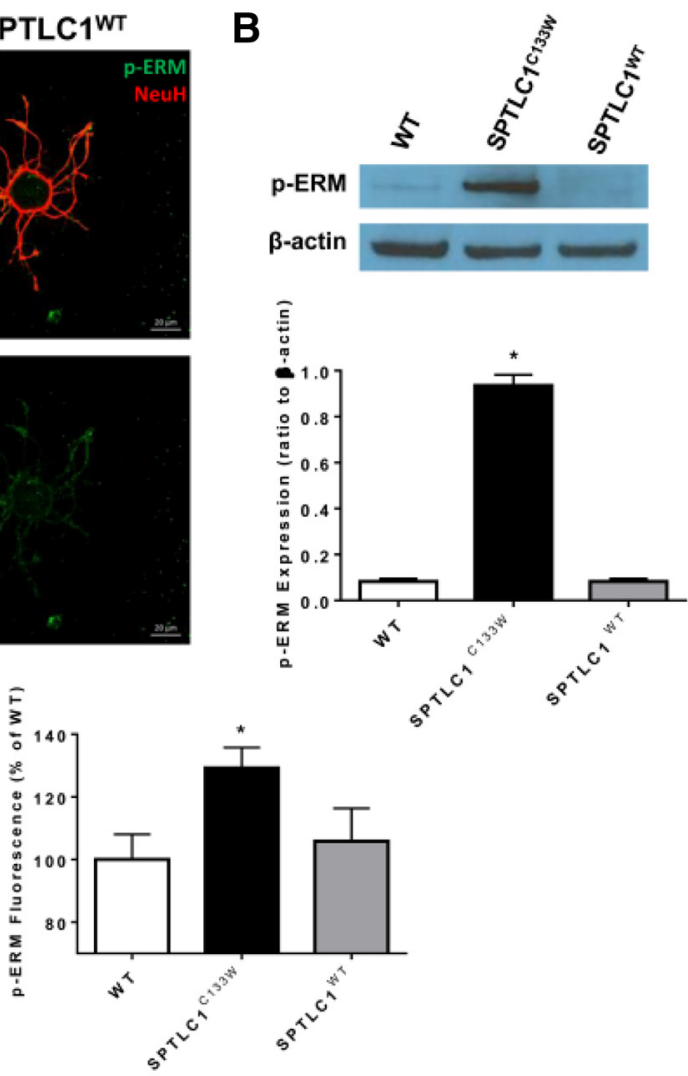

$\mathbf{F}$

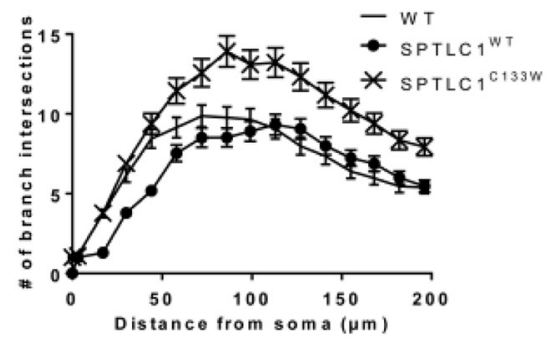

Figure 1. Characterization of the mutant SPTLC1 ${ }^{\mathrm{C} 133 \mathrm{~W}}$ DRG phenotype in in vitro. A, DRG from WT, SPTLC1 ${ }^{\mathrm{C} 133 \mathrm{~W}}$, and SPTLC1 ${ }^{\mathrm{WT}}$ mice $(n=3)$ were stained with p-ERM and NeuH. Scale bar, 20 $\mu \mathrm{m} . \boldsymbol{B}$, Western blot revealing an increase in p-ERM in SPTLC1 ${ }^{\mathrm{C} 133 \mathrm{~W}}$, but not in WT or SPTLC1 ${ }^{\mathrm{WT}}$, DRG. C, SPTLC1 ${ }^{\mathrm{C} 133 \mathrm{~W}}$ DRG had significantly longer neurite length compared with WT and SPTLC1 ${ }^{\text {WT }}$. $D$, Expression of p-ERM at the neuronal growth cone is significantly elevated in SPTLC1 ${ }^{C 133 \mathrm{~W}}$ DRG compared with WT and SPTLC1 ${ }^{\mathrm{WT}}$. E, Soma size of DRG showed no significant difference across all groups. F, Sholl analysis revealed increased neuronal branching in SPTLC1 ${ }^{\mathrm{C} 133 \mathrm{~W}}$ DRG compared with WT and SPTLC1 ${ }^{\text {WT. }}$

ous in vivo studies found that varying L-serine or L-alanine levels can influence disease severity in HSN-1 (Garofalo et al., 2011), we examined their role in DRG growth in vitro.

\section{Materials and Methods}

Transgenic mice. Generation of transgenic mice has been described previously (McCampbell et al., 2005). Overexpression of WT and C133W mutant copy of SPTLC1 was driven by the chicken $\beta$-actin promoter. Mice were generated in the BL6/C57 background. SPTLC1 ${ }^{\mathrm{C} 133 \mathrm{~W}}$ mice were HSN-1 models and WT and SPTLC1 ${ }^{\mathrm{WT}}$ mice were controls.

Neuronal culture. Mice were anesthetized and killed at 6 months of age. Experiments were conducted with DRG from three male animals per genotype. DRG were extracted, digested with $0.05 \%$ trypsin (Life Technologies), and collagenase-IV/dispase $(1 \mathrm{mg} / \mathrm{ml}$ and $0.25 \mathrm{mg} / \mathrm{ml}$; Worthington Biochemical); resuspended in DMEM (Life Technologies) with $10 \%$ fetal bovine serum (Atlanta Biologicals) and DNase-I (Sigma-Aldrich); and triturated with heat-polished Pasteur pipettes. On chamber slides precoated with poly-D-lysine and laminin (Sigma-Aldrich), cells were plated in neurobasal or L-alanine-free medium (AFM) supple- mented with 2\% B27 (Life Technologies). Neurobasal medium is modified DMEM with optimized concentrations of components (Brewer et al., 1993). However, because neurobasal medium contains L-alanine, we developed AFM for use in our experiments. AFM was prepared using DMEM with optimized formulation of certain components $(0.4 \mathrm{mM}$ L-asparagine, $0.26 \mathrm{~mm}$ L-cysteine, $0.5 \mathrm{~mm}$ L-glutamate, $0.06 \mathrm{~mm}$ L-proline, $5 \times 10^{-6} \mathrm{~mm}$ vitamin $\mathrm{B} 12$, and $26.1 \mathrm{~mm}$ sodium bicarbonate).

Amino acid supplementation. After plating, cells were supplemented with L-serine or L-alanine at a final concentration of $10 \mathrm{~mm}$ (SigmaAldrich) and grown for $2 \mathrm{~d}$ in vitro (DIV).

SPT inhibition. After $1 \mathrm{DIV}$, cells were treated with myriocin (Santa Cruz Biotechnology) at a final concentration of 10 or $20 \mu \mathrm{M}$.

Immunofluorescence. Cells were fixed in $4 \%$ paraformaldehyde (Affymetrix). Primary antibodies were added in blocking solution containing 2\% normal goat serum (Vector Labs) and $0.1 \%$ Triton X-100 (Sigma-Aldrich) overnight. Cells were washed and incubated with secondary antibodies for $1 \mathrm{~h}$. Antibodies were against phosphorylated-ERM (rabbit anti-phospho-ezrin/radixin/moesin, 1:700; Cell Signaling Technology), neurofilament-heavy-chain (mouse-monoclonal SMI-32R, 
A
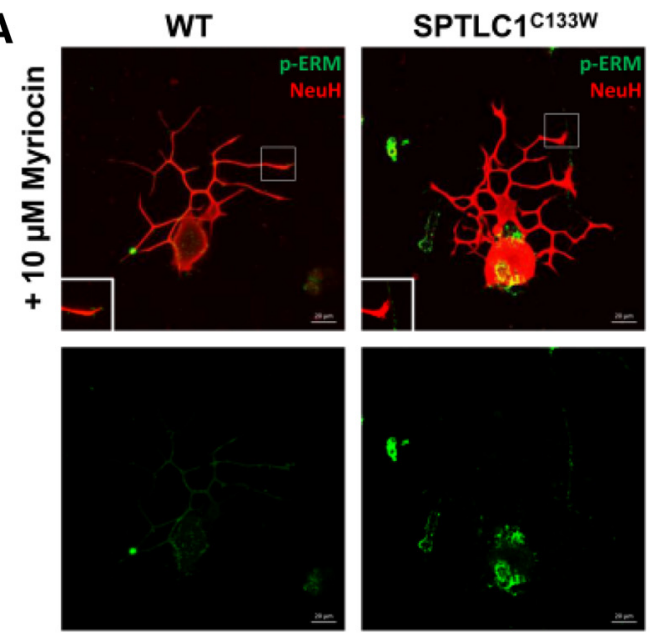

C

E

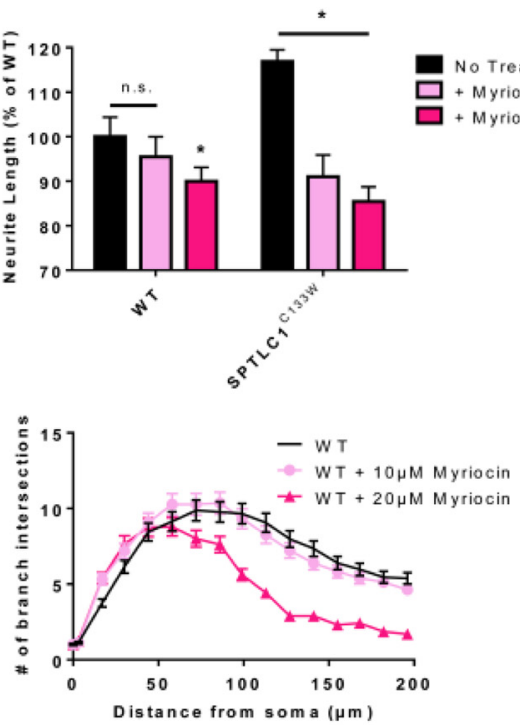

B

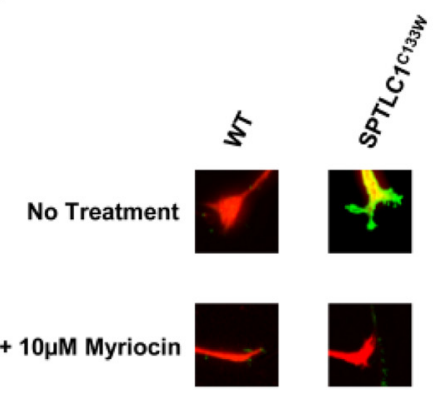

D

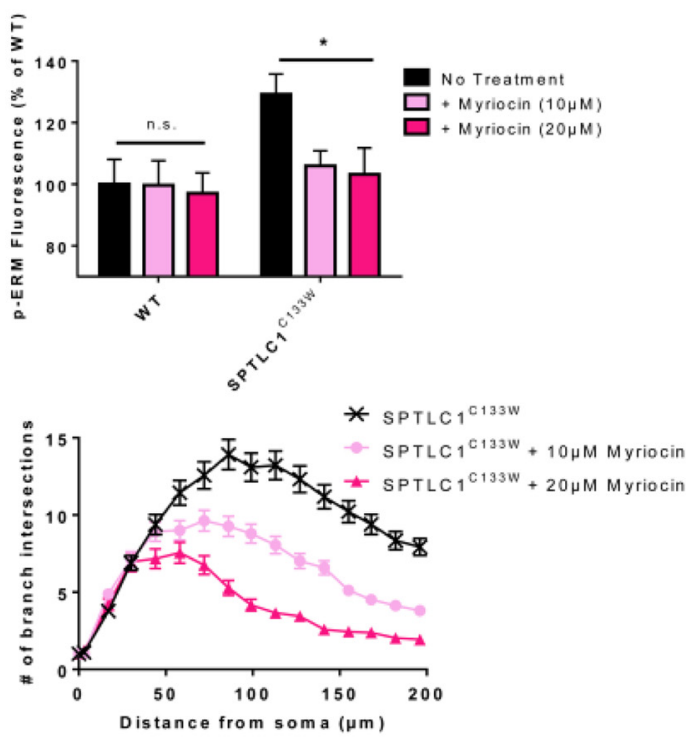

Figure 2. SPT inhibition via myriocin alleviates the mutant SPTLC1 ${ }^{133 \mathrm{~W}}$ condition. $A$, DRG from WT and SPTLC1 ${ }^{\mathrm{C} 133 \mathrm{~W}}$ mice treated with $10 \mu \mathrm{m}$ myriocin $(n=3)$ were stained with $\mathrm{p}$-ERM and NeuH. Scale bar, $20 \mu \mathrm{m}$. B, Representative images of WT and SPTLC1 ${ }^{C 133 \mathrm{~W}}$ DRG growth cones before and after treatment. $C$, WT DRG exhibit significantly decreased neurite length when treated with $20 \mu \mathrm{m}$ myriocin, but not at $10 \mu \mathrm{m}$. SPTLC1 ${ }^{\mathrm{C} 133 \mathrm{~W}}$ DRG show significantly decreased neurite length after 10 and $20 \mu \mathrm{m}$ myriocin treatments. D, There is no significant difference in p-ERM expression at the growth cones of WT DRG after treatment with 10 or $20 \mu \mathrm{m}$ myriocin. In SPTLC1 ${ }^{C 133 \mathrm{~W}}$ DRG, $\mathrm{p}$-ERM expression is significantly reduced after 10 and $20 \mu \mathrm{m}$ myriocin treatments. E, Sholl analysis revealed no difference in branching of WT DRG after $10 \mu \mathrm{m}$ myriocin, but a reduction at $20 \mu \mathrm{m}$. $\boldsymbol{F}$, Branching of SPTLC1 ${ }^{\mathrm{C} 133 \mathrm{~W}}$ DRG after 10 and $20 \mu \mathrm{m}$ myriocin treatments is decreased in a dose-dependent manner.

1:700; Covance), goat anti-rabbit Alexa Fluor 488, and goat anti-mouse Alexa Fluor 555 (1:200; Life Technologies).

Western blotting. DRG were collected in RIPA buffer (Sigma-Aldrich) with Complete Protease Inhibitor Cocktail (Roche). Samples were separated on NuPAGE 4-12\% Bis-tris gels (Invitrogen), transferred onto PVDF membranes, blocked with $5 \%$ milk in PBS containing $0.05 \%$ Tween 20 , and probed with antibody against phosphorylated-ERM (1: 1000 ) and $\beta$-actin (rabbit anti- $\beta$-actin, 1:5000; Santa Cruz Biotechnology). Membranes were developed with SuperSignal West Pico Chemiluminescent Substrate (Thermo Scientific) after incubation with HRP-conjugated secondary antibodies (Abcam).

Microscopy and analysis. Images were captured using Zeiss LSM510 confocal microscope and Zen 2009 software, keeping exposure/gain settings constant. Analyses were performed on ImageJ software by a blinded experimenter, with minimum 18 neurons analyzed per mouse. Using the NeuronJ plug-in, the longest neurite length of a DRG was measured, the average value calculated for the neurons of each mouse, and the mean neurite length derived from the three average values per genotype (subsequent mean values were determined similarly). Neurites were traced manually from the soma outward, excluding those $<10 \mu \mathrm{m}$. For branch- ing, the Sholl analysis plug-in was used to quantify branch intersections. Neurons with considerable overlap were excluded to avoid overestimation. The expression of p-ERM was measured as the mean fluorescence intensity (MFI) in neuronal growth cones. The MFI were background subtracted and averaged. Soma size was quantified by manually tracing the area around the neuron. All quantitative data were normalized to the WT control.

Statistics. Statistical analyses were performed on GraphPad Prism 6. Genotype comparisons among SPTLC $1^{\mathrm{C} 133 \mathrm{~W}}$, SPTLC1 ${ }^{\mathrm{WT}}$, and WT were analyzed via one-way ANOVA. Comparisons after treatment (myriocin, L-serine, L-alanine, and AFM) were analyzed via two-way ANOVA. Analyses were followed up by Bonferroni's post hoc tests. The criterion for significance was ${ }^{\star} p<0.05$. Error bars are expressed as \pm SEM.

\section{Results}

Mutant DRG exhibit increased neurite growth in vitro

After extraction from the spinal cord, DRG began to grow neuronal processes in vitro. Initial characterization revealed mor- 
A
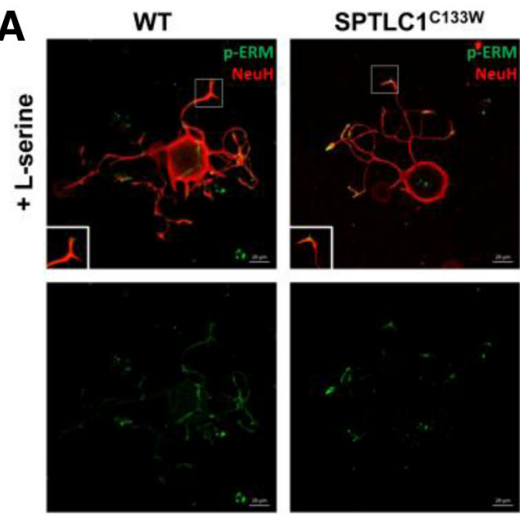

D

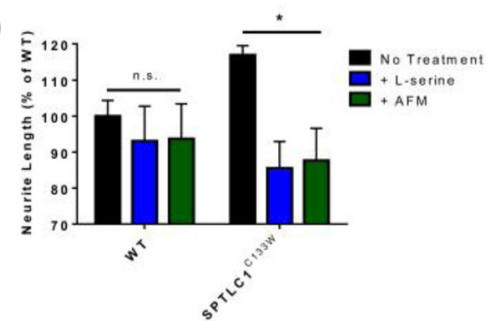

F

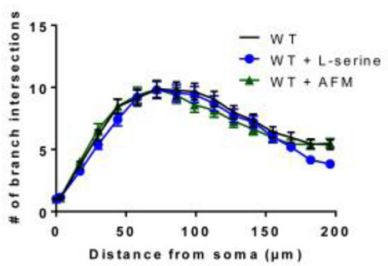

B
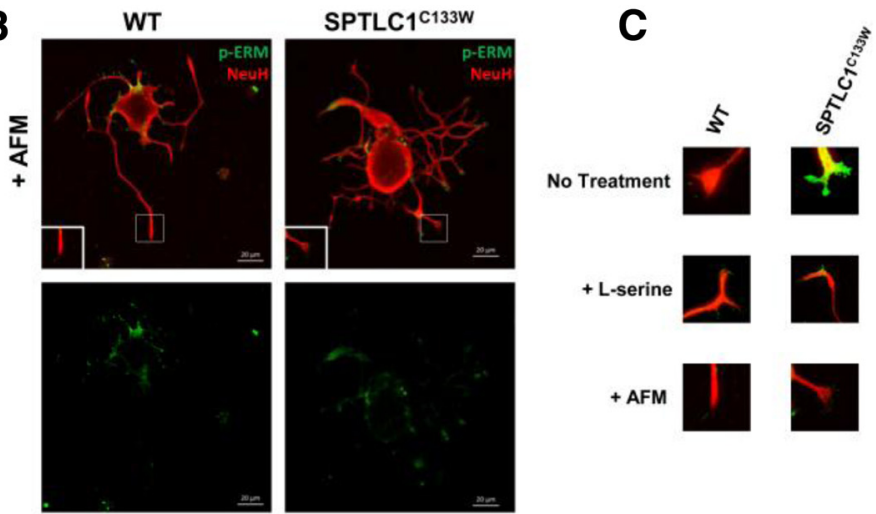

E

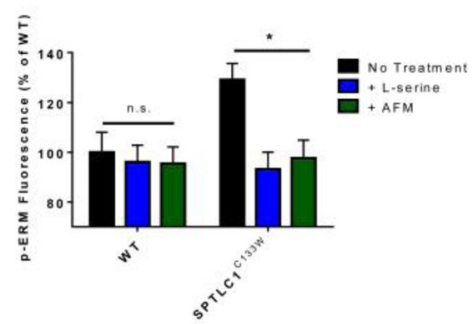

G

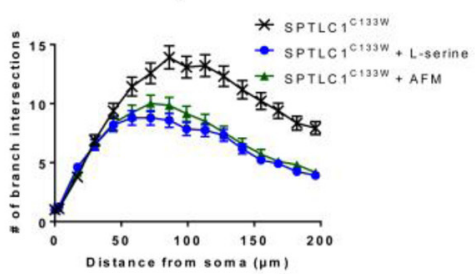

Figure 3. Supplementation with L-serine or removal of L-alanine rescues the mutant SPTLC1 ${ }^{\mathrm{C} 133 \mathrm{~W}}$ condition. $\boldsymbol{A}, \boldsymbol{B}, \mathrm{DRG}$ from WT and SPTLC1 ${ }^{\mathrm{C} 133 \mathrm{~W}}$ mice treated with $10 \mathrm{~mm} \mathrm{L-serine}(\boldsymbol{A})$ or with AFM $(\boldsymbol{B})(n=3)$ were stained with p-ERM and NeuH. Scale bar, $20 \mu \mathrm{m}$. $\boldsymbol{C}$, Representative images of WT and SPTLC1 ${ }^{\mathrm{C} 133 \mathrm{~W}}$ DRG growth cones before and after treatment. $\boldsymbol{D}$, SPTLC1 ${ }^{\mathrm{C} 133 \mathrm{~W}}$ DRG treated with L-serine or AFM exhibit significantly decreased neurite length. WT DRG show no significant difference in neurite length after L-serine or AFM. $\boldsymbol{E}$, Expression of p-ERM is significantly decreased in SPTLC $1{ }^{\mathrm{C} 133 \mathrm{~W}}$ DRG growth cones after treatment with L-serine or AFM. There is no significant difference in p-ERM expression in WT DRG after L-serine or AFM. F, Sholl analysis revealed no difference in branching of WT DRG after L-serine or AFM treatment. G, Branching of SPTLC1 ${ }^{\text {C133W }}$ DRG after L-serine or AFM treatment is reduced to levels similar to WT DRG.

phology of mutant SPTLC1 ${ }^{\text {C133W }}$ DRG (Fig. $1 A$ ). To eliminate the possibility of the transgene overexpression having adverse effects, SPTLC1 ${ }^{\text {WT }}$ DRG were also used as controls. WT and SPTLC $1{ }^{\text {WT }}$ DRG were not significantly different in any quantitative measures analyzed in this study. Compared with controls, SPTLC $1{ }^{\mathrm{C} 133 \mathrm{~W}}$ DRG exhibited a marked $29.2 \%$ increase $\left({ }^{*} p=\right.$ $\left.0.002,{ }^{\star} p=0.004\right)$ in $p$-ERM expression at neuronal growth cones, as detected by immunofluorescence and Western blotting (Fig. $1 B, D$ ). Mutant SPTLC1 ${ }^{\mathrm{C} 133 \mathrm{~W}}$ DRG also exhibited a $16.9 \%$ increase $\left({ }^{\star} p=0.004,{ }^{\star} p=0.011\right)$ in neurite length and branching compared with controls (Fig. 1C,F), suggesting that the mutation is regulating axon elongation at neuronal growth cones. Quantification of soma size revealed no significant differences across all conditions (Fig. 1E) and we found no evidence of apoptosis (data not shown).

\section{SPT inhibition rescues the mutant phenotype}

We confirmed whether the mutant SPTLC1 ${ }^{\mathrm{C} 133 \mathrm{~W}}$ phenotype was linked to mutant enzymatic activity by using myriocin, a SPT inhibitor. WT and SPTLC1 ${ }^{\mathrm{C} 133 \mathrm{~W}}$ DRG were treated with 10 or 20 $\mu \mathrm{M}$ myriocin (Fig. $2 A$ ). After treatment, we found that the expression of p-ERM at the neuronal growth cone was significantly decreased $\left({ }^{*} p=0.003,{ }^{*} p=0.004\right)$ in SPTLC1 ${ }^{\mathrm{C} 133 \mathrm{~W}}$ DRG by $13.3 \%$ and $15.8 \%$ (Fig. $2 B, D$ ), which corresponded with $15.86 \%$ and $31.46 \%$ decreases in neurite length $\left({ }^{*} p=0.003,{ }^{\star} p<0.001\right.$; Fig. 2C). However, myriocin had minimal effects on WT DRG, only reaching significance at the $20 \mu \mathrm{M}$ concentration $\left({ }^{*} p=\right.$ 0.021 ), which decreased neurite length by $15.8 \%$ (Fig. $2 C, D$ ). In terms of branching, myriocin led to a dose-dependent decrease in SPTLC1 ${ }^{\mathrm{C} 133 \mathrm{~W}}$ DRG, but only showed a noticeable effect at $20 \mu \mathrm{M}$ in WT DRG (Fig 2 E, F). Overall, the mutant SPTLC1 ${ }^{\mathrm{C} 133 \mathrm{~W}}$ condition, but not the WT, responds strongly to SPT inhibition.

Restorative effects of L-serine supplementation or L-alanine removal on mutant DRG

Supplementation with either L-serine or L-alanine has been shown to influence myelination, axon diameter, and sensory performance of HSN-1 mice (Garofalo et al., 2011). Specifically, excess L-serine ameliorates peripheral neuropathic symptoms, whereas excess L-alanine exacerbates those symptoms. Here, we found that the mutant condition was rescued when SPTLC1 ${ }^{\mathrm{C} 133 \mathrm{~W}}$ DRG were treated with $10 \mathrm{~mm} \mathrm{~L}$-serine (Fig. $3 \mathrm{~A}$ ). Not only did L-serine lead to a $31.36 \%$ decrease $\left({ }^{*} p=0.001\right)$ in neurite length and branching of mutant SPTLC $1{ }^{\text {C133W }}$ DRG (Fig. $3 D, G)$, it also reduced the expression of p-ERM by $36 \%\left({ }^{*} p<\right.$ 0.001 ) to resemble the WT level (Fig. $3 A, C$ ). Conversely, L-serine had no significant effects on the WT neurite length or p-ERM expression ( $p=0.155, p=0.351$; Fig. $3 A, D-F)$.

Further, removal of L-alanine had similar restorative effects as L-serine supplementation on SPTLC1 ${ }^{\mathrm{C} 133 \mathrm{~W}}$ DRG (Fig. 3B). When cultured in AFM, the mutant neurons exhibited a $29.2 \%$ decrease $\left({ }^{\star} p=0.012\right)$ in neurite length and branching (Fig. 

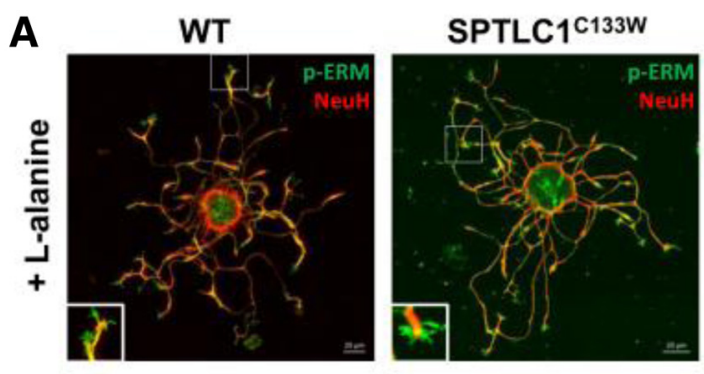

\section{B}
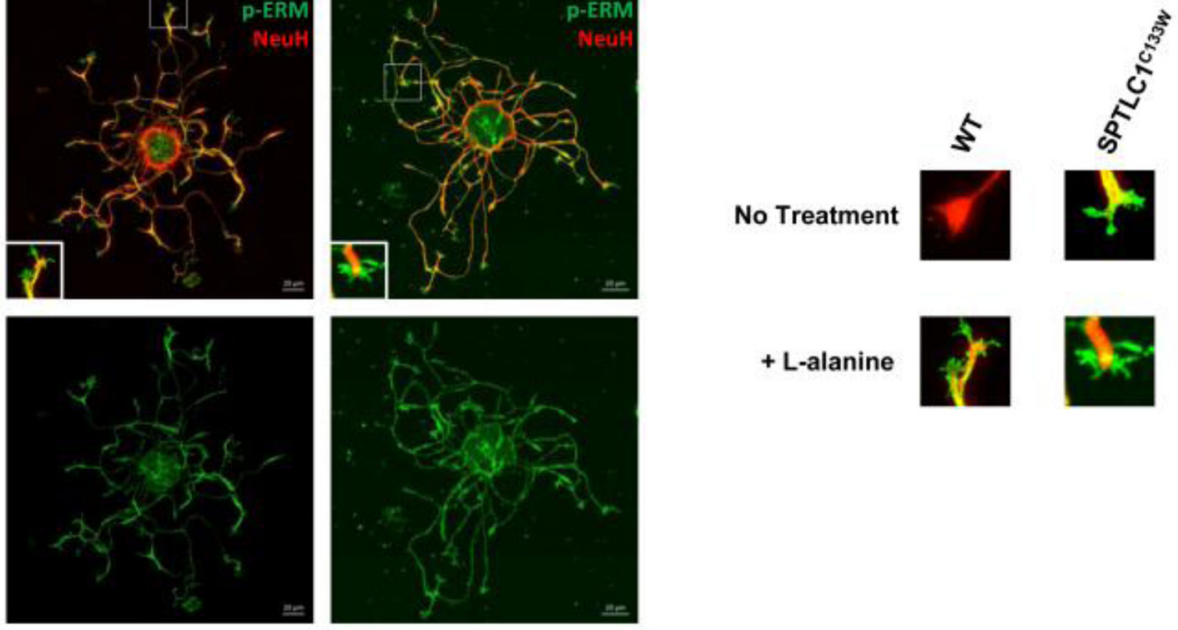

C
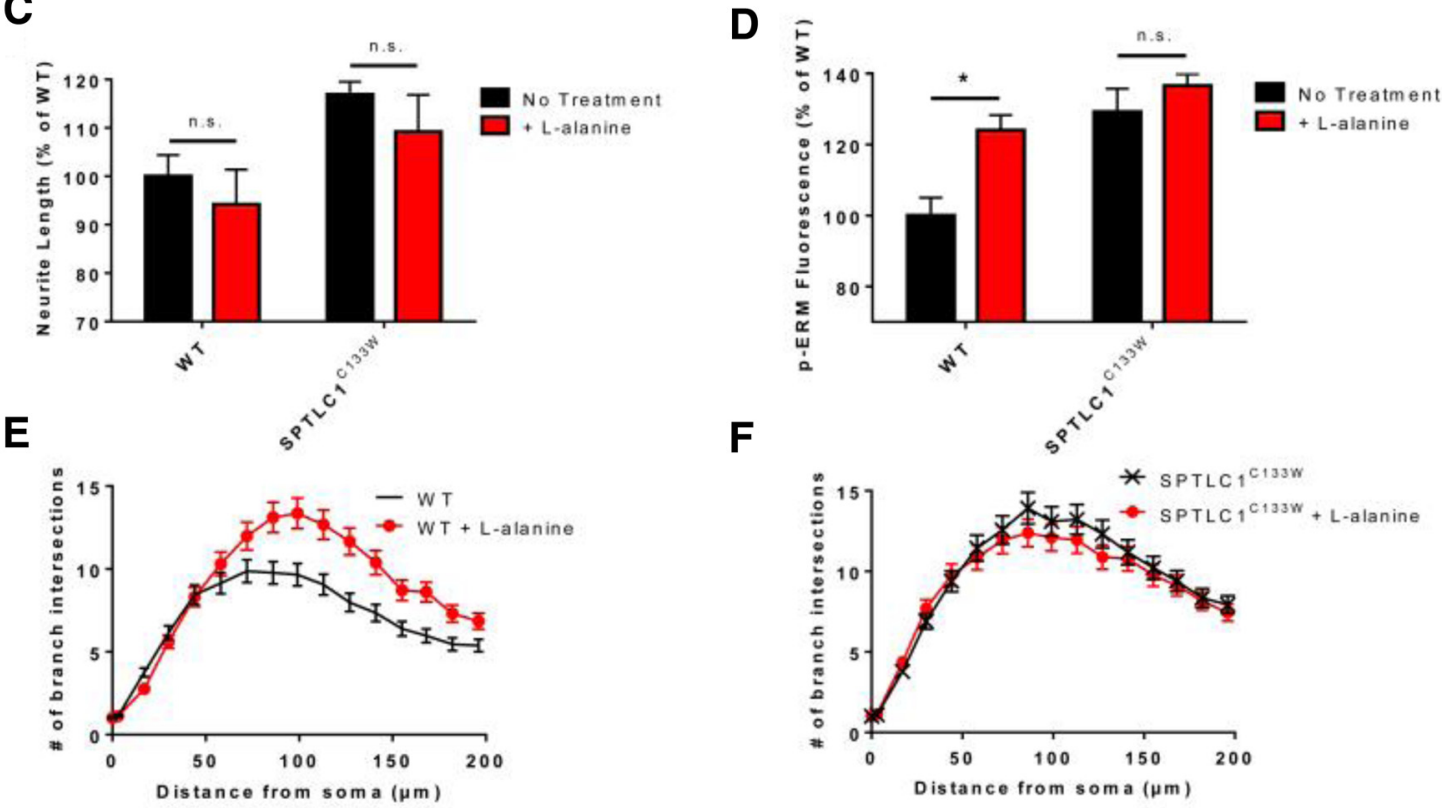

Figure 4. Supplementation with L-alanine increases WT DRG branching and p-ERM expression. $A$, DRG from WT and SPTLC1 ${ }^{133 W}$ mice treated with $10 \mathrm{~mm} L$-alanine $(n=3)$ were stained with p-ERM and NeuH. Scale bar, $20 \mu \mathrm{m} . \boldsymbol{B}$, Representative images of WT and SPTLC $1{ }^{\mathrm{C} 133 \mathrm{~W}}$ DRG growth cones before and after treatment. C, Treatment with L-alanine has no significant effect on neurite length of WT or SPTLC1 ${ }^{C 133 W}$ DRG. D. Expression of p-ERM is significantly increased in WT DRG growth cones after L-alanine treatment. L-alanine treatment had no significant effect on p-ERM expression in SPTLC1 ${ }^{\mathrm{C} 133 \mathrm{~W}}$ DRG. E, Sholl analysis revealed branching of WT DRG after L-alanine treatment is elevated to levels similar to mutant SPTLC1 ${ }^{\mathrm{C} 133 \mathrm{~W}}$ DRG. $F$, Branching of SPTLC1 ${ }^{\mathrm{C133W}}$ DRG is not altered after L-alanine treatment.

$3 D, G)$ and a $31.58 \%$ reduction in $\mathrm{p}$-ERM expression $\left({ }^{*} p=\right.$ 0.001 ; Fig. $3 C, E)$. The absence of L-alanine had no significant effects on the WT condition ( $p=0.211, p=0.304$; Fig. $3 B, D-F)$.

\section{Excess L-alanine alters WT phenotype}

Conversely, when treated with excess $10 \mathrm{~mm}$ L-alanine, mutant SPTLC1 ${ }^{\text {C133W }}$ DRG showed no significant differences in neurite length $(p=0.095)$, branching, or $p$-ERM expression $(p=0.131$; Fig. $4 A, C, D, F)$. However, WT DRG treated with excess L-alanine in part resembled the mutant phenotype (Fig. 4A): branching was elevated and p-ERM expression was increased by $24 \%\left({ }^{*} p=0.004\right)$ to resemble the mutant condition (Fig. $4 B, D, E)$. Although we also expected an increase in WT neurite length, we found no significant difference ( $p=0.116$; Fig. $4 C$ ), suggesting that mechanisms of neuronal branching via growth cone proteins such as p-ERM is more susceptible to L-alanine availability than neurite outgrowth from the soma itself.

\section{Discussion}

Mutations in genes encoding subunits of SPT are one of the most common causes of hereditary sensory neuropathies (Dawkins et al., 2001; Rotthier et al., 2011, 2012). Although the progressive axonopathy and accumulation of atypical sphingolipid metabolites in HSN-1 suggests putative neurotoxicity (Penno et al., 2010), it remains poorly understood how the altered activity of mutant SPT leads to selective damage of the PNS.

Our current in vitro study provides evidence of increased neuronal growth and branching after extraction of DRG from HSN-1 mice and its dependence upon SPT substrate availability. We observed corresponding increases of p-ERM expression in the 
neuronal growth cones of SPTLC $1{ }^{\mathrm{C} 133 \mathrm{~W}}$ DRG, implicating these actin-cross-linking proteins as regulators of neurite growth. The increased neurite growth could be a result of elevated p-ERM in mutant DRG, which can aid axon elongation via attractive growth cone guidance or modulation of adhesion to the plasma membrane (Marsick et al., 2012). Further, the upregulation of growth cone proteins such as ERM has been linked to neuroregeneration after injury (Haas et al., 2004). However, the current in vitro model of neurite growth does not include a preconditioned in vivo injury, suggesting that the mutant morphology is indicative of compensatory rather than regenerative growth. Because progression of HSN-1 pathology is often exacerbated by peripheral injury in patients, a detailed investigation of the injury response in HSN-1 and how it affects the regulation of p-ERM and other relevant growth cone proteins may help to elucidate their role in the PNS.

Although it has been suggested that sphingolipid metabolites (Canals et al., 2010; Gandy et al., 2013) and various kinases (Ramesh 2004) can regulate p-ERM activation, how mutant SPT in HSN-1 leads to ERM phosphorylation is not known. We previously reported increased levels of TNF- $\alpha$ in SPTLC1 ${ }^{\mathrm{Cl} 133 \mathrm{~W}}$ DRG and sciatic nerves (Eichler et al., 2009). This proinflammatory cytokine can act downstream via PKC or p38 MAPK to phosphorylate ERM proteins (Koss et al., 2006). Further, it is conceivable that canonical sphingolipid levels may be disrupted in HSN-1 due to altered activity of the mutant SPT enzyme. Although existing data on canonical sphingolipid levels in HSN-1 remain inconclusive (Dawkins et al., 2001; Dedov et al., 2004), the accumulation of neurotoxic deoxysphingolipids is well described (Eichler et al., 2009; Rotthier et al., 2011). Previous studies have reported that exogenous treatment of at least $1 \mu \mathrm{M}$ deoxysphingolipids caused neurite loss and apoptosis (Cuadros et al., 2000; Penno et al., 2010). Endogenous levels are lower, however, ranging from 100 to $500 \mathrm{~nm}$ in plasma (Penno et al., 2010; Rotthier et al., 2011). We suggest that these metabolites may affect neuronal growth and viability indirectly via regulation of kinase activity (Hannun and Bell, 1987; Sánchez et al., 2008; Fyrst and Saba, 2010), alterations in sphingolipid metabolism (Dawkins et al., 2001; Zitomer et al., 2009), or disruption of cellular membranes (Jiménez-Rojo et al., 2014). A closer examination into how mutant SPT regulates these pathways and alters ERM activation will be important to help understand the molecular mechanisms of disease progression in $\mathrm{HSN}-1$.

Because mutant SPT preferentially incorporates L-alanine over L-serine (Gable et al., 2010; Penno et al., 2010), we manipulated their availability in vitro. The beneficial effects of L-serine upon behavior and nerve pathology in HSN-1 mice have been described previously (Garofalo et al., 2011). We demonstrate rescue of the SPTLC $1{ }^{\mathrm{C} 133 \mathrm{~W}}$ condition, not only after L-serine supplementation, but also after removal of L-alanine, presumably due to restoration of canonical SPT activity. Despite its increased affinity for L-alanine, mutant SPT retains residual affinity for L-serine $\left(K_{\mathrm{m}}=\sim 1.4 \mathrm{mM}\right.$ and $V_{\max }=\sim 275 \mathrm{pmol} / \mathrm{mg} / \mathrm{min}$ vs wild-type $K_{\mathrm{m}}=\sim 0.75 \mathrm{~mm}$ and $V_{\max }=\sim 1350 \mathrm{pmol} / \mathrm{mg} / \mathrm{min}$; Gable et al., 2010), with the result that mutant SPT can still incorporate L-serine, especially in the case of excess L-serine or lack of L-alanine.

Conversely, L-alanine supplementation elevated branching and p-ERM expression in WT DRG to resemble the mutant condition, which is not surprising because L-alanine exacerbates peripheral neuropathic symptoms in HSN-1 mice (Garofalo et al., 2011). However, because both L-serine and L-alanine are gluconeogenic amino acids involved in pathways regulating oxidative stress and neurotransmission (Rowsell et al., 1969; de Koning et al., 2003; Grosser et al., 2004; Fuchs et al., 2006), we cannot categorically rule out that the observed effects on DRG were due to their metabolic and neurotrophic properties.

Indeed, L-serine is crucial for lipid synthesis, neuronal survival, and function in the CNS (de Koning and Klomp, 2004; Hirabayashi and Furuya, 2008). In the absence of L-serine, neurons from the CNS do not grow as robustly as those treated with L-serine in vitro, because glia are the main suppliers of L-serine to neurons in vivo (Savoca et al., 1995; Furuya et al., 2000). After neuronal insult, the PNS receives glial support needed for regeneration (Scheib and Höke, 2013). This trophic activity is important for axons, especially those in the metabolically isolated PNS (Nave, 2010). Glia in the PNS tend to ensheath axons in a much lower ratio (1:1) than in the CNS (up to 60:1), emphasizing the importance of the neuron-glia interaction in peripheral nerves (Nave and Werner, 2014). Therefore, the distinct environment of the PNS may render peripheral axons susceptible to certain metabolic fluctuations. Our current in vitro data show contrasting effects of $\mathrm{L}$-serine and L-alanine upon the mutant DRG phenotype, indicating a selective vulnerability to these amino acids, as suggested by studies of HSN-1 mice (Garofalo et al., 2011). Manipulating the L-serine/L-alanine ratio in HSN-1 may be of broader relevance to other peripheral nerve disorders and sphingolipidoses.

Here, we describe aberrant morphology of SPTLC1 ${ }^{\mathrm{C} 133 \mathrm{~W}}$ DRG characterized by increased neurite growth, branching, and expression of p-ERM at neuronal growth cones. This phenotype indicates that neurite growth is being altered by the SPTLC1 ${ }^{\mathrm{C} 133 \mathrm{~W}}$ mutation and is suggestive of compensatory growth in vitro. Because the eventual course of HSN-1 is distal axonal degeneration, it will be important to understand how the mutation in vivo leads to a lengthdependent axonopathy. Further, because SPT inhibition and treatment with the canonical SPT substrate L-serine was able to rescue the mutant phenotype of elevated p-ERM, a detailed examination into how the mutation regulates the expression of important growth cone proteins will help ro identify therapeutic targets for HSN-1.

\section{References}

Bejaoui K, Wu C, Scheffler MD, Haan G, Becausehby P, Wu L, de Jong P, Brown RH Jr (2001) SPTLC1 is mutated in hereditary sensory neuropathy, type 1. Nat Genet 27:261-262. CrossRef Medline

Brewer GJ, Torricelli JR, Evege EK, Price PJ (1993) Optimized survival of hippocampal neurons in B27-supplemented neurobasal ${ }^{\mathrm{TM}}$, a new serumfree medium combination. J Neurosci Res 35:567-576. CrossRef Medline

Canals D, Jenkins RW, Roddy P, Hernández-Corbacho MJ, Obeid LM, Hannun YA (2010) Differential effects of ceramide and sphingosine-1phosphate on ERM phosphorylation. J Biol Chem 285:32476-32485. CrossRef Medline

Cuadros R, Montejo de Garcini E, Wandosell F, Faircloth G, FernándezSousa JM, Avila J (2000) The marine compound spisulosine, an inhibitor of cell proliferation, promotes the disassembly of actin stress fibers. Cancer Lett 152:23-29. CrossRef Medline

Dawkins JL, Hulme DJ, Brahmbhatt SB, Auer-Grumbach M, Nicholson GA (2001) Mutations in SPTLC1, encoding serine palmitoyltransferase, long chain base subunit-1, cause hereditary sensory neuropathy type I. Nat Genet 27:309-312. CrossRef Medline

Dedov VN, Dedova IV, Merrill AH Jr, Nicholson GA (2004) Activity of partially inhibited serine palmitoyltransferase is sufficient for normal sphingolipid metabolism and viability of HSN1 patient cells. Biochem Biophys Acta 1688:168-175. Medline

de Koning TJ, Klomp LW (2004) Serine deficiency syndromes. Curr Opin Neurol 17:197-204. CrossRef Medline

de Koning TJ, Snell K, Duran M, Berger R, Poll-The BT, Surtees R (2003) L-Serine in disease and development. Biochem J 371:653-661. CrossRef Medline

Eichler FS, Hornemann T, McCampbell A, Kuljis D, Penno A, Vardeh D, 
Tamrazian E, Garofalo K, Lee HJ, Kini L, Selig M, Frosch M, Gable K, von Eckardstein A, Woolf CJ, Guan G, Harmon JM, Dunn TM, Brown RH Jr (2009) Overexpression of the wild-type SPT1 subunit lowers deoxysphingolipid levels and rescues the phenotype of HSAN1. J Neurosci 29: 14646-14651. CrossRef Medline

Fuchs SA, Dorland L, de Sain-vna der Velden MG, Hendriks M, Klomp LW, Berger R, de Koning TJ (2006) D-serine in the developing human central nervous system. Ann Neurol 60:476-480. CrossRef Medline

Furuya S, Tabata T, Mitoma J, Yamada K, Yamasaki M, Makino A, Yamamoto T, Watanabe M, Kano M, Hirabayashi Y (2000) L-serine and glycine serve as major astroglia-derived trophic factors for cerebellar Purkinje neurons. Proc Natl Acad Sci U S A 97:11528-11533. CrossRef Medline

Fyrst H, Saba JD (2010) An update on sphingosine-1-phosphate and other sphingolipid mediators. Nat Chem Biol 6:489-497. CrossRef Medline

Gable K, Han G, Monaghan E, Bacikova D, Natarajan M, Williams R, Dunn TM (2002) Mutations in the yeast $L C B 1$ and $L C B 2$ genes, including those corresponding to the hereditary sensory neuropathy type I mutations, dominantly inactivate serine palmitoyltransferase. J Biol Chem 277: 10194-10200. CrossRef Medline

Gable K, Gupta SD, Han G, Niranjanakumari S, Harmon JM, Dunn TM (2010) A disease-causing mutation in the active site of serine palmitoyltransferase causes catalytic promiscuity. J Biol Chem 285:22846-22852. Medline

Gandy KA, Canals D, Adada M, Wada M, Roddy P, Snider AJ, Hannun YA, Obeid LM (2013) Sphingosine-1-phosphate induces filopodia formation through S1PR2 activation of ERM proteins. Biochem J 449:661-672. Medline

Garofalo K, Penno A, Schmidt BP, Lee HJ, Frosch MP, von Eckardstein A, Brown RH, Hornemann T, Eichler FS (2011) Oral L-serine supplementation reduces production of neurotoxic deoxyphingolipds in mice and humans with hereditary sensory autonomic neuropathy type 1 . J Clin Invest 121:4735-4745. CrossRef Medline

Gonzalez-Agosti C, Solomon F (1996) Response of radixin to perturbations of growth cone morphology and motility in chick sympathetic neurons in vitro. Cell Motility Cytoskel 34:122-136. CrossRef Medline

Grosser N, Oberle S, Berndt G, Erdmann K, Hemmerle A, Schröder H (2004) Antioxidant action of L-alanine; heme oxygenase- 1 and ferritin as possible mediators. Biochem Biophys Res Comm 314:351-355. CrossRef Medline

Haas MA, Vickers JC, Dickson TC (2004) Binding partners L1 cell adhesion molecule and the ERM proteins are involved in development and regenerative response to injury of hippocampal and cortical neurons. Eur J Neurosci 20:1436-1444. Medline

Hannun YA, Bell RM (1987) Lysosphingolipids inhibit protein kinase C: implications for the sphingolipidoses. Science 235:670-674. CrossRef Medline

Hirabayashi Y, Furuya S (2008) Roles of L-serine and sphingolipid synthesis in brain development and neuronal survival. Prog Lipid Res 47:188-203. CrossRef Medline

Jiménez-Rojo N, Sot J, Busto JV, Shaw WA, Duan J, Merrill AH Jr, Alonso A, Goñi FM (2014) Biophysical properties of novel 1-deoxy-(dihydro)ceramides occuring in mammalian cells. Biophys J 107:2850-2859. CrossRef Medline

Khan LA, Zhang H, Abraham N, Sun L, Fleming JT, Buechner M, Hall DH, Gobel $\mathrm{V}$ (2013) Intracellular lumen extension requires ERM-1-dependent apical membrane expansion and AQP-8-mediated flux. Nat Cell Biol 15:143-156. CrossRef Medline
Koss M, Pfeiffer GR 2nd, Wang Y, Thomas ST, Yerukhimovich M, Gaarde WA, Doerschuk CM, Wang Q (2006) Ezrin/Radixin/Moesin proteins are phosphorylated by TNF- $\alpha$ and modulate permeability increases in human pulmonary microvascular endothelial cells. J Immunol 176:1218 1227. CrossRef Medline

Marsick BM, San Miguel-Ruiz JE, Letourneau PC (2012) Activation of Ezrin/Radixin/Moesin mediates attractive growth cone guidance through regulation of growth cone actin and adhesion receptors. J Neurosci 32: 282-296. CrossRef Medline

McCampbell A, Truong D, Broom DC, Allchorne A, Gable K, Cutler RG, Mattson MP, Woolf CJ, Frosch MP, Harmon JM, Dunn TM, Brown RH Jr (2005) Mutant SPTLC1 dominantly inhibits serine palmitoyltransferase activity in vivo and confers an age-dependent neuropathy. Hum Mol Gen 14:3507-3521. CrossRef Medline

Nave KA (2010) Myelination and the trophic support of long axons. Nat Rev Neurosci 11:275-283. CrossRef Medline

Nave KA, Werner HB (2014) Myelination of the nervous system: mechanisms and functions. Annu Rev Cell Dev Biol 30:503-533. CrossRef Medline

Penno A, Reilly MM, Houlden H, Laurá M, Rentsch K, Niederkofler V, Stoeckli ET, Nicholson G, Eichler F, Brown RH Jr, von Eckardstein A, Hornemann T (2010) Hereditary sensory neuropathy type 1 is caused by the accumulation of two neurotoxic sphingolipids. J Biol Chem 285: 11178-11187. CrossRef Medline

Ramesh V (2004) Merlin and the ERM proteins in Schwann cells, neurons and growth cones. Nat Rev Neurosci 5:462-470. CrossRef Medline

Rowsell EV, Snell K, Carnie JA, Al-Tai AH (1969) Liver L-alanine-glyoxylate and L-serine-pyruvate aminotransferase activities: an apparent association with gluconeogenesis. Biochem J 115:1071-1073. CrossRef Medline

Rotthier A, Penno A, Rautenstrauss B, Auer-Grumbach M, Stettner GM, Becauseselbergh B, Van Hoof K, Sticht H, Lévy N, Timmerman V, Hornemann T, Janssens $\mathrm{K}$ (2011) Characterization of two mutations in the SPTLC1 subunit of serine palmitoyltransferase associated with hereditary sensory and autonomic neuropathy type 1. Hum Mutat 32:E2211-E2225. CrossRef Medline

Rotthier A, Baets J, Timmerman V, Janssens K (2012) Mechanisms of disease in hereditary sensory and autonomic neuropathies Nat Rev Neurosci 8:73-85.

Sánchez AM, Malagarie-Cazenave S, Olea N, Vara D, Cuevas C, Díaz-Laviada I (2008) Spisulosine (ES-285) induces prostate tumor PC-3 and LNCaP cell death by de novo synthesis of ceramide and $\mathrm{PKC} \zeta$ activation. Eur J Pharmacol 584:237-245. CrossRef Medline

Savoca R, Ziegler U, Sonderegger P (1995) Effects of L-serine on neurons in vitro. J Neurosci Methods 61:159-167. CrossRef Medline

Scheib J, Höke A (2013) Advances in peripheral nerve regeneration. Nat Rev Neurol 9:668-676. CrossRef Medline

Wadsworth JM, Clarke DJ, McMahon SA, Lowther JP, Beattie AE, LangridgeSmith PR, Broughton HB, Dunn TM, Naismith JH, Campopiano DJ (2013) The chemical basis of serine palmitoyltransferase inhibition by myriocin. J Am Chem Soc 135:14276-14285. CrossRef Medline

Zitomer NC, Mitchell T, Voss KA, Bondy GS, Pruett ST, Garnier-Amblard EC, Liebeskind LS, Park H, Wang E, Sullards MC, Merrill AH Jr, Riley RT (2009) Ceramide synthase inhibition by Fumonisin $B_{1}$ causes accumulation of 1-deoxysphinganine. J Biol Chem 284:4786-4795. CrossRef Medline 